\title{
PLANEJAMENTO DO TURISMO MUNICIPAL E A LEI NN 1261/2015: PRINCIPAIS CONTRIBUIÇÕES
}

\author{
Renata Maria Ribeiro, Danielli Cristina Granado Romero, Fábio Luciano Violin, Thais Marques \\ Picchi
}

Universidade Estadual Paulista - UNESP, Turismo, Campus Experimental de Rosana, SP. E-mail: renata@rosana.unesp.br

\section{RESUMO}

O planejamento é uma prática imprescindível ao turismo. A atividade envolve vários setores produtivos como o transporte, alimentação, hospedagem, e a infraestrutura urbana envolvendo políticas que possam orientar a atividade. Nessa perspectiva, em 2015, o governo do estado São Paulo criou a Lei 12/61 que estabelece critérios para criação de Municípios de Interesse Turístico MIT e Estâncias Turísticas. Esse estudo objetivou conhecer a Lei, e observar as atitudes tomadas pelos municípios para conquistar o título de MIT. Adotou-se como metodologia a pesquisa bibliográfica e documental e o acompanhamento das ações no município de Panorama -SP. Em uma visão preliminar, observou-se uma modificação na visão do município na formulação de sua política para obtenção do título, e ainda a busca do conhecimento técnico e da articulação dos atores locais para efetivação das ações em torno do turismo.

Palavras-chave: Planejamento do turismo, Município de Interesse Turístico - MIT, Lei no1261/2015, política de turismo.

\section{MUNICIPAL TOURISM PLANNING AND LAW NO. 1261/2015: MAIN CONTRIBUTIONS}

\begin{abstract}
Planning is an essential practice for tourism. The activity involves several productive sectors such as transportation, food, lodging, and urban infrastructure involving policies that can guide the activity. In this perspective, in 2015, the São Paulo state government created Law 12/61 that establishes criteria for the creation of Municipalities of Tourist Interest - MIT and Tourist Resorts. This study aimed to know the Law, and to observe the attitudes taken by the municipalities to conquer the title of MIT. The bibliographical and documentary research and the follow-up of the actions in the municipality of Panorama -SP were adopted as methodology. In a preliminary view, there was a change in the vision of the municipality in the formulation of its policy to obtain the title, as well as the search for technical knowledge and the articulation of the local actors to carry out actions around tourism.
\end{abstract}

Keywords: Tourism planning, Municipality of Tourist Interest - MIT, Law no. 1261/2015, Tourism policy.

\section{INTRODUÇÃO}

O planejamento do turismo apresenta algumas particularidades, e para sua efetiva execução, deve considerar a comunidade receptora, a infraestrutura básica, a oferta turística existente e a demanda para tal oferta.

Beni (1998, p. 108) relata que o planejamento "do ponto de vista governamental consiste, no seu sentido mais lato, em um processo que estabelece objetivos, define linhas de ação e planos detalhados para atingi-los, e determina os recursos necessários para sua consecução". 
A organização da atividade no Brasil possui a diretriz nas políticas públicas desde o âmbito nacional, perpassando ao estadual, ao regional e ao municipal, em uma escala de competências descentralizadas, mas altamente conexas e que direcionam a gestão pública ao planejamento da atividade e ainda, direcionam "a gestão privada para que ela estruture empreendimentos turísticos lucrativos com base na responsabilidade socioambiental"(BRAGA, 2007, p.8), e ainda nos preceitos da participação ativa nas decisões, observando os princípios da sustentabilidade do destino.

O Brasil discute estratégias para o desenvolvimento do turismo por meio de Planos de Política Nacional de Turismo dede a década de 1990 e que se estrutura e se modifica até a presente data (2017). Esse alinhamento constante permitiu a organização e geração de novos de destinos.

A partir dessa política passou-se a observar que não somente cidades já receptoras de visitantes, mas outras, também poderiam gerar produtos turísticos diferenciados para atender uma parcela da população crescente em termos de busca de lazer.

A estrutura adotada e inserida nos municípios para o desenvolvimento do turismo foi a do planejamento participativo subdividido em várias fases, baseada nas Teorias de Planejamento Turístico e na qualificação dos atores locais à gestão da atividade.

\section{As fases do Planejamento}

A estrutura do planejamento em turismo consiste em apoiar a técnica nos preceitos da Teoria dos Sistemas (Bertalanffy, 1973) e que posteriormente foi adaptada à administração e ao turismo. No Brasil, os estudos nessa linha estão até os dias de hoje apoiados na Teoria do Sistema de Turismo - SISTUR de Beni (1998), sendo utilizadas amplamente na academia, na política de turismo nacional e também na política de planejamento no estado de São Paulo.

Mesmo sendo uma referência traçada a mais de dez anos, essa teoria se mostra eficaz à execução do planejamento municipal para o turismo.

Segundo BENI (2006) as fases do processo de planejamento turístico são: INVENTÁRIO de recursos naturais, culturais e artificiais, identificação e descrição da região objeto de estudo (em que se utiliza a Teoria do espaço Turístico de BOULLÓN, 2002), observação do perfil socioeconômico da região bem como dos serviços e equipamentos turísticos e da infraestrutura de apoio ao turismo.

Após essa fase tem-se como ferramenta o DIAGNÓSTICO que analisa em quais condições os recursos ambientais, culturais e os bens e serviços se dispõe para atender a demanda turística e o PROGNÓSTICO, com metodologias específicas que geram respostas aos gestores sobre como formular políticas e diretrizes de reorientação para o turismo.

Mas a técnica metodológica e a visão política pouco se coordenam por isso observa-se que o obstáculo ao desenvolvimento do turismo apresenta-se no fato da dificuldade quanto à definição deste setor nas pastas da administração pública, pois até a década de 1990 poucos estados e municípios possuíam secretarias específicas para atender à necessidade do planejamento e gestão do turismo. Àquela época a atividade não se identificava claramente como setor econômico diferenciado. Ainda hoje, muitas cidades não estabelecem padrões sobre as ações do turismo junto à administração pública.

Mesmo a economia gerada em torno do turismo não está diretamente ligada ao setor, pois nas pesquisas econômicas municipais pode-se perceber o pouco conhecimento que se tem em torno da geração de receita e de empregos diretos e indiretos que envolvem a cadeia produtiva do turismo. Pode-se afirmar ainda que os bens e serviços vendidos aos visitantes e turistas domésticos originam-se de vários segmentos da produção e que, em alguns casos só é vendida aos turistas uma parte dessa produção e o restante se destina as outras formas de demanda final ou usos intermediários. A afirmação de que a hierarquia dada à atividade varia de 
acordo com o momento e ainda, em relação aos outros setores da economia nacional parece clara, eis que quando há mudanças políticas envolvendo cargos de confiança nas secretarias, os projetos deixam de ser executados, pois, parecem estar em simbiose com disputas ou entraves políticos que sempre causam prejuízos e atrasos aos processos de planejamento e ordenamento municipal.

Há ainda a disparidade de critérios, não existindo ideias claras a respeito das ações, estratégias, pessoal especializado ou mesmo processos metodológicos adequados e eficientes, capazes de fixar meios de determinar a continuidade ou mesmo o lugar da atividade turística na organização administrativa do setor público.

O descaso para com a importância e a relevância que a atividade turística foi tratada até pouco tempo, gerou instabilidade da pasta junto aos ministérios, secretarias estaduais e municipais verificadas ainda hoje. O que geralmente ocorre é que a cada gestão pública, a condução dessa atividade ganha destaque ou desinteresse por parte dos gestores nas diversas esferas do setor público.

Outra questão é que a tendência ao lazer e ao turismo estão relacionados ao tempo e aos recursos disponíveis, o que gera a possibilidade de planejar destinos pouco tradicionais, de interior e com proposta diversificada.

Nessa tendência, os destinos podem atrair pessoas em um raio de abrangência de até 200 $\mathrm{km}$, possibilitando a organização de mais destinos que possam atender ao turismo em feriados prolongados e fins de semana.

\section{A Lei Complementar no 1261/2015}

O Estado de São Paulo tem instruído a política das Estâncias Turísticas desde a década de 1947. Ao todo atualmente o Estado de São Paulo possui 70 Estâncias.

A legislação pertinente às Estâncias remonta o incentivo por parte do Estado de recursos financeiros a serem aplicados na melhoria da infraestrutura que possibilite a melhoria das cidades estâncias para o fortalecimento da atividade turística.

Em face da possibilidade de desenvolvimento de novos destinos foi aprovado em 2015 pela Assembleia Legislativa a Lei no 1261 de 29 de abril que além de manter as 70 (setenta) estâncias denomina a possibilidade de que 140 (cento e quarenta) municípios do estado de São Paulo possam se tornar Município de Interesse Turístico - MIT. A lei instrui critérios para a escolha aos quais:

No capítulo II apesar de referir-se à Estância Turística, aplica-se a exigência de que os Municípios de Interesse possuam os critérios subscritos nos incisos II, VI e VII.

Capítulo II - Das Estâncias Turísticas

Artigo 2 o são condições indispensáveis e cumulativas para classificação de Município como Estância Turística (também para Municípios de Interesse Turístico - inserção e grifo nosso)

II - possuir expressivos atrativos turísticos de uso público e caráter permanente, naturais, culturais ou artificiais, que identifiquem a sua vocação voltada para algum ou alguns dos segmentos abaixo relacionados, sintetizados no Anexo I desta lei complementar:
a) Turismo Social;
h) Turismo Náutico;
b) Ecoturismo;
i) Turismo de Aventura;
c) Turismo Cultural;
j) Turismo de Sol e Praia;
d) Turismo Religioso;
k) Turismo de Negócios e Eventos;
e) Turismo de Estudos e de Intercâmbio;
I) Turismo Rural;
f) Turismo de Esportes;
m) Turismo de Saúde.
g) Turismo de Pesca; 
VI - ter um plano diretor de turismo, aprovado e revisado a cada 3 (três) anos;

VII - manter Conselho Municipal de Turismo devidamente constituído e atuante.

§ 10 - O Conselho Municipal de Turismo, de caráter deliberativo, deve ser constituído, no mínimo, por representantes das organizações da sociedade civil representativas dos setores de hospedagem, alimentação, comércio e receptivo turístico, além de representantes da administração municipal nas áreas de turismo, cultura, meio ambiente e educação.

§ 20 - Cada Conselho terá regimento próprio, com regras para a eleição de seu presidente e duração do respectivo mandato.

Já o Capítulo III trata especificamente das exigências que precisam ser inseridas no Plano de Diretor de Desenvolvimento Turístico, descritas detalhadamente, inclusive com o endereçamento dos locais, fotografias e horários de funcionamento.

CAPÍTULO III Dos Municípios de Interesse Turístico - MIT

Artigo 40 - São condições indispensáveis e cumulativas para a classificação de Município como de Interesse Turístico:

I - ter potencial turístico;

II - dispor de serviço médico emergencial e, no mínimo, dos seguintes equipamentos e serviços turísticos: meios de hospedagem no local ou na região, serviços de alimentação e serviço de informação turística;

III - dispor de infraestrutura básica capaz de atender às populações fixas e flutuantes no que se refere a abastecimento de água potável e coleta de resíduos sólidos;

IV - possuir expressivos atrativos turísticos, plano diretor de turismo e Conselho Municipal de Turismo, nos mesmos termos previstos nos incisos II, VI e VII do artigo 20 desta lei complementar.

E ainda, a cartilha de instruções exige a formação do Conselho Municipal de Turismo composto por $60 \%$ de membros da iniciativa privada e associações, e $40 \%$ dos órgãos públicos. Sendo que na oportunidade de apresentação do plano junto à Assembleia Legislativa conste as atas das reuniões do referido conselho.

a) estudo da demanda turística existente no ano anterior à apresentação do projeto, a ser realizado pela Prefeitura Municipal em convênio com órgão público estadual, federal, instituição de ensino superior ou entidade especializada;

b) inventário, subscrito pelo Prefeito Municipal, dos atrativos turísticos do município, de que trata o inciso II do artigo 20 desta lei complementar, com suas respectivas localizações e vias de acesso; c) inventário, subscrito pelo Prefeito Municipal, dos equipamentos e serviços turísticos, do serviço de atendimento médico emergencial e da infraestrutura básica de que tratam os incisos II e III do artigo 40 desta lei complementar;

d) cópia do Plano Diretor Municipal de Turismo e atas das 6 (seis) últimas reuniões do Conselho Municipal de Turismo, devidamente registradas em cartório (SÃO PAULO, 2015).

A estrutura de inventário, a necessidade de confecção de Plano Diretor de Turismo entre outras informações, estão embasadas nas estruturas de planejamento adotadas por autores do turismo e também nas prerrogativas do Ministério do Turismo, e servem de instrumento de organização e compilação de informações para o planejamento do turismo municipal.

Não obstante a necessidade de formalização, os municípios que já possuem visitação e um fluxo de visitantes iniciou o processo organização dos materiais.

\section{METODOLOGIA}


O estudo passou por uma fase de levantamento de legislações e documentos do município de Panorama a fim de observar quais as atitudes tomadas para ajuste e conformidade à Lei $1261 / 2015$. A base do estudo foi a análise do Plano Diretor de Desenvolvimento Turístico 2017 formulado pelo município e por equipe de alunos e professores do Curso de Turismo da UNESP.

\section{Objeto de Estudo}

O município de Panorama localiza-se no extremo oeste do Estado de São Paulo, na divisa com Mato Grosso do Sul, na latitude 2121"23" sul, e na longitude 51이"35" oeste, e pertence a 10a Região Administrativa do Estado, que tem como cidade sede Presidente Prudente. Atualmente, o município conta com uma população de 15.539 habitantes segundo IBGE (2016).

O atrativo de Panorama é o Balneário à beira do rio Paraná. Com uma estrutura de área de banho, banheiros, churrasqueiras, lanchonetes, estacionamento e ampla área verde, o balneário atrai durante o verão número considerável de visitantes da região. 0 município realiza eventos regionais com público externo também. Em face dessas e outras características, o mesmo realizou o Plano.

\section{RESULTADOS E DISCUSSÕES}

A pesquisa em torno da legislação local relacionada diretamente ao turismo, constata que o município possui vocação, fluxo de visitantes e a preocupação de organizar a atividade turística desde 1999. Isso pode ser comprovado pelo quadro de leis compiladas.

Leis relativas ao turismo anteriores a composição do Plano Diretor de Turismo

\begin{tabular}{|c|c|c|c|}
\hline $\begin{array}{l}\text { Número } \\
\text { da Lei }\end{array}$ & Data & Emenda & Comentário \\
\hline $63 / 1999$ & 23/11/1999 & Lei de Criação do FUMTUR & $\begin{array}{l}\text { Lei que se destina a delimitar } \\
\text { conta de recursos específico para } \\
\text { o turismo; }\end{array}$ \\
\hline $093 / 2010$ & $30 / 03 / 2010$ & $\begin{array}{l}\text { Autoriza o Executivo Municipal a } \\
\text { firmar convênio com a associação } \\
\text { Circuito Oeste Rios }\end{array}$ & $\begin{array}{l}\text { Denota vontade política em inserir } \\
\text { o município às ações de } \\
\text { planejamento do turismo regional }\end{array}$ \\
\hline $131 / 2011$ & $15 / 02 / 2011$ & $\begin{array}{l}\text { Cria o Conselho Municipal de } \\
\text { Turismo }\end{array}$ & $\begin{array}{llr}\text { Menciona } & \text { competências } \\
\text { membros } & \text { participantes } \\
\text { COMTUR } & & \end{array}$ \\
\hline $165 / 2011$ & $21 / 06 / 2011$ & Alteração da lei 131/2011 & $\begin{array}{l}\text { Numera o quantitativo de } \\
\text { membros do COMTUR, bem como } \\
\text { quais as entidades participantes } \\
\text { do mesmo. }\end{array}$ \\
\hline $191 / 2011$ & $08 / 11 / 2011$ & $\begin{array}{l}\text { Dispõe sobre a obrigatoriedade } \\
\text { dos estabelecimentos comerciais, } \\
\text { hotéis, motéis, casas noturnas e } \\
\text { similares a anexar aviso em local } \\
\text { visível sobre os crimes praticados } \\
\text { contra crianças e adolescentes e } \\
\text { suas penas, e dá outras } \\
\text { providências. }\end{array}$ & $\begin{array}{l}\text { Atende às prerrogativas do } \\
\text { princípio da não exploração } \\
\text { infantil, inclusive em atendimento } \\
\text { à Política Nacional de turismo do } \\
\text { MTUR. }\end{array}$ \\
\hline $381 / 2014$ & $16 / 09 / 2014$ & $\begin{array}{l}\text { Dispõe sobre a criação de } \\
\text { empregos e dá outras providências }\end{array}$ & $\begin{array}{l}\text { Criação de quadro de funcionários } \\
\text { "Guarda Vidas Municipal". Ação } \\
\text { importante para atender à }\end{array}$ \\
\hline
\end{tabular}

Colloquium Socialis, Presidente Prudente, v. 01, n. Especial 2, Jul/Dez, 2017, p.860-866. DOI: 10.5747/cs.2017.v01.nesp2.s0240 


\begin{tabular}{|l|l|l|l|}
\hline & & & $\begin{array}{l}\text { demanda de turistas visitantes do } \\
\text { Balneário municipal. }\end{array}$ \\
\hline $422 / 2015$ & $23 / 06 / 2015$ & $\begin{array}{l}\text { Aprova o Plano de Gestão } \\
\text { Integrada de Resíduos Sólidos }\end{array}$ & $\begin{array}{l}\text { Importante projeto estruturado } \\
\text { para atender os princípios da } \\
\text { sustentabilidade em conformidade } \\
\text { com a Lei Federal no 12.305 de } \\
12 / 08 / 2010 .\end{array}$ \\
\hline
\end{tabular}

FONTE: Plano Diretor de Desenvolvimento Turístico de Panorama, 2017.

A leitura do Plano Diretor de Desenvolvimento Turístico indicou que os parâmetros solicitados na Lei 1261/2015 foram cumpridos, e que há características estruturantes e concernentes à que o município seja considerado de Interesse Turístico. Um outro indicador importante constatado no município está relacionado à participação da população. A estruturação do Conselho e as reuniões realizadas e comprovadas no Plano de Turismo corroboram que as pessoas participam junto ao poder público de ações e decisões para a continuidade das atividades e das estratégias de desenvolvimento do turismo, não só relativos ao principal atrativo (balneário) mas para desenvolver outros produtos que atraiam visitantes.

\section{CONCLUSÃO}

Tendo como princípio o planejamento turístico como uma das principais funções à organização municipal para o desenvolvimento da atividade, a leitura da Lei 1261/2015 averiguou que outrora, quando da instituição das estâncias turísticas não havia um critério técnico o suficiente para definir exigências atreladas a uma possível destituição do "status" de Estância, prova disso é a constatação de que algumas das Estâncias ainda em 2017 não possuem Plano Diretor de Desenvolvimento Turístico e estão se adequando agora. Em uma observação e destaque aos que pleiteiam o título de MIT observou-se ao menos no caso de Panorama, a seriedade do trabalho que se iniciou em abril de 2016 com a confecção das etapas de inventário, diagnóstico e prognóstico, entrega do plano em 2017 e continuidade das ações e reuniões do Conselho Municipal de Turismo junto às esferas da municipalidade.

Entende-se que a legislação, bem como uma nova postura da Secretaria Estadual de Turismo de São Paulo estão em busca de um ajuste de conduta e de seleção de destinos que realmente estejam se consolidando como turísticos, e que invariavelmente irão necessitar de mais apoio das políticas estaduais para sua consolidação. Nessa perspectiva, torna-se importante que ações e critérios de análise cada vez mais técnicas e transparentes uma vez que devem estar imbricadas de ações de planejamento envolvendo estratégias de desenvolvimento turístico como alternativa econômica em regiões que estejam se sobressaindo pelo fluxo de visitantes.

A análise referente ao objetivo da pesquisa que era conhecer a Lei 1261/2015, e observar as atitudes tomadas pelos municípios para conquistar o título de MIT, foram atingidos, uma vez que conclui-se que a Lei 1261/2015 está baseada em critérios técnicos das teorias de planejamento do turismo, que busca o planejamento participativo a partir da exigência de conselho de turismo, que solicita informações sobre as demandas de visitantes e os motivos de sua estada no município que está pleiteando o título, que define sob critérios do Ministério do Turismo a classificação de tipos de turismo e solicita que o município informe quais já existem e quais podem ser potencializados.

Outrossim, a leitura do Plano Diretor de Desenvolvimento Turístico de Panorama descreve os itens solicitados de modo conciso e ordenado de acordo com a Cartilha de orientação formulada pela Secretaria de Estado do Turismo -SP. Esse procedimento e sua consequente organização infere ao município uma ordem de estratégias a serem adotadas que deverão possibilitar a plena execução do plano e a compilação de dados que deverão ser apresentados em 
uma linha temporal de três anos. Certamente, há necessidade de continuidade das ações, uma vez que a execução e os resultados sendo positivos qualificam o município a receber recursos financeiros para o desenvolvimento do turismo municipal.

Concorda-se com SILVA quando menciona as políticas inovadoras "estas políticas públicas inovadoras são cada vez mais descentralizadas, para se adaptarem à estrutura e às condições da realidade local, o que torna ainda mais complexa a capacidade governamental de propor, estabelecer, implementar e avaliar políticas"(SILVA, 2012, p. 15).

Em relação política de turismo para o planejamento da atividade percebe-se uma nova condução ao desenvolvimento das estruturas formais públicas, tendo em vista que a sociedade local pleiteia uma organização municipal que conduza o município à uma atividade econômica baseada no setor terciário. A mesma e o turista poderão usufruir de lazer a partir de lugares ao ócio, de uma estrutura de serviços mais abrangente, uma vez o planejamento a longo prazo delineia destinos mais qualificados aos visitantes e aos empreendedores das diversas áreas que atendem ao turismo. Sabe-se que o Plano ainda está em fase de análise e que Panorama ainda não possui o título pleiteado. Entretanto, observa-se independente dessa decisão, que o município está realizando as ações contidas no Plano Diretor de Desenvolvimento Turístico.

\section{REFERÊNCIAS BIBLIOGRÁFICAS}

BENI, M.C. Análise Estrutural do Turismo. 2a. Ed. São Paulo: ed. SENAC, 1998.

BENI, M.C. Política e planejamento de turismo no Brasil. São Paulo: Aleph, 2006.

BENI, M.C. Análise Estrutural do Turismo. 12ạ. Ed. São Paulo: ed. SENAC, 2007.

BOULLÓN, Roberto C. Planejamento do espaço turístico. Bauru, SP: EDUSC, 2002.

BRAGA, D.C. Planejamento Turístico: teoria e prática. Rio de Janeiro: Elsevier: Campus 2007.

PREFEITURA MUNICIPAL DE PANORAMA. Plano Diretor de Desenvolvimento Turístico de Panorama, 2017. Disponível em acervo municipal.

SÃO PAULO. Assembleia Legislativa. Estabelece condições e requisitos para a classificação de Estâncias e de Municípios de Interesse Turístico e dá providências correlatas. São Paulo, 2015. Disponível em: http://www.al.sp.gov.br/norma/?id=174594.

SÃO PAULO. Secretaria de Turismo do Governo do Estado de São Paulo. Cartilha de orientação para Municípios de Interesse Turístico de acordo com a Lei 1261/2015. Disponível em: http://www.turismo.sp.gov.br/publico/include/download.php?file=199

SILVA, C. L. Políticas Públicas e desenvolvimento local. (org.) Petrópolis, RJ: Vozes, 2012. 